\title{
Complexity of Cardiotocographic Signals as A Predictor of Labor
}

\author{
João Monteiro-Santos ${ }^{1,2, *}$, Teresa Henriques ${ }^{1,2}$, Inês Nunes ${ }^{2,3,4}\left(\mathbb{D}\right.$, Célia Amorim-Costa ${ }^{2,3,5}$, \\ João Bernardes ${ }^{2,5,6}$ and Cristina Costa-Santos ${ }^{1,2}$ \\ 1 Department of Community Medicine, Information and Health Decision Sciences-MEDCIDS, Faculty of \\ Medicine, University of Porto, 4200-450 Porto, Portugal; teresasarhen@med.up.pt (T.H.); \\ csantos@med.up.pt (C.C.-S.) \\ 2 Center for Health Technology and Services Research-CINTESIS, Faculty of Medicine, University of Porto, \\ 4200-450 Porto, Portugal; imnunes@icbas.up.pt (I.N.); celcosta@med.up.pt (C.A.-C.); \\ joaobern@med.up.pt (J.B.) \\ 3 Department of Obstetrics and Gynecology, Centro Materno-Infantil do Norte-Centro Hospitalar do Porto, \\ 4200-450 Porto, Portugal \\ 4 Instituto de Ciências Biomédicas Abel Salazar, University of Porto, 4200-450 Porto, Portugal \\ 5 Department of Gynecology-Obstetrics and Pediatrics, Faculty of Medicine of University of Porto, \\ 4200-450 Porto, Portugal \\ 6 Centro Hospitalar Universitário de S. João, Alameda Hernâni Monteiro, 4200-101 Porto, Portugal \\ * Correspondence: up200806742@med.up.pt; Tel.: +351-2-2551-3622
}

Received: 14 November 2019; Accepted: 13 January 2020; Published: 16 January 2020

\begin{abstract}
Prediction of labor is of extreme importance in obstetric care to allow for preventive measures, assuring that both baby and mother have the best possible care. In this work, the authors studied how important nonlinear parameters (entropy and compression) can be as labor predictors. Linear features retrieved from the SisPorto system for cardiotocogram analysis and nonlinear measures were used to predict labor in a dataset of 1072 antepartum tracings, at between 30 and 35 weeks of gestation. Two groups were defined: Group A-fetuses whose traces date was less than one or two weeks before labor, and Group B-fetuses whose traces date was at least one or two weeks before labor. Results suggest that, compared with linear features such as decelerations and variability indices, compression improves labor prediction both within one (C-Statistics of 0.728 ) and two weeks (C-Statistics of 0.704). Moreover, the correlation between compression and long-term variability was significantly different in groups A and B, denoting that compression and heart rate variability look at different information associated with whether the fetus is closer to or further from labor onset. Nonlinear measures, compression in particular, may be useful in improving labor prediction as a complement to other fetal heart rate features.
\end{abstract}

Keywords: labor; fetal heart rate; entropy; data compression; complexity analysis; nonlinear analysis; preterm

\section{Introduction}

Worldwide, approximately 15 million infants are born preterm (after less than 37 completed weeks of gestation) each year [1]. Over one-third of the world's estimated 3 million annual neonatal deaths are related to preterm birth [2-4]. Even after surviving the neonatal period, infants born preterm are at increased risk of delayed childhood development and low economic productivity [5]. Therefore, interventions to reduce the preterm birth rate are of utmost importance.

Clinical decisions during labor and delivery in developed countries are strongly based on cardiotocography (CTG) [6-8], which has been one of the most used tools in assessing fetal wellbeing 
since the early '60s. CTG combines fetal heart rate (FHR), obtained using a Doppler ultrasound probe or electrocardiogram electrodes, with uterine contractions (UC) measurements, obtained using an abdominal or intra-uterine pressure transducer. Both provide relevant information about the fetal condition and early detection of preterm labor and abnormal labor progress $[7,9,10]$.

Despite the importance of assessing the wellbeing of the fetus and mother, poor agreement among physicians in the analysis and classification of CTGs is still a problem, even among experienced obstetricians, resulting in a high false positive rate $[6,11,12]$. In daily practice, FHR and UC are displayed on a printout or monitor to be visually interpreted by a clinician. Even when following specific, well-accepted guidelines (for example, the International Federation of Obstetrics and Gynecology (FIGO), associated with high sensitivity and low specificity [13]), interpretation of CTG relies on the clinician's opinion and daily practice. This leads to a chance that adherence to conventional guidelines could be more harmful than beneficial [14].

The beat-to-beat variation of FHR reflects the influence of the fetus' autonomic nervous system (ANS) and its components (sympathetic and parasympathetic) in the heart. Therefore, it is an indicator of the fetal pathophysiological status, which can be used in the assessment of fetal wellbeing [15] and its well-known influence on labor onset and progression [16]. A certain level of unpredictable fetal heart rate variability (fHRV) reflects sufficient capabilities of the organism in search of optimal behavior. Reduced fHRV is linked with limited capabilities and mental disorders [17]. The linear modeling approach is used to quantify sympathetic and parasympathetic control mechanisms and their balance through the measurement of spectral low- and high-frequency components. However, it has been shown that not all information carried by beat-to-beat variability can be explained by these components [18]. For this matter, in the past couple of decades, and with the fast development of computation, new signal processing and pattern recognition methodologies (namely entropy and compression) have been developed and applied to many different fields, including the analysis of fHRV $[19,20]$. These approaches can reveal relevant clinical information not exposed by temporal or frequency analysis [21].

Systems, such as Omniview SisPorto [22-24] and NST-Expert, which later became CAFE [25], can automatically deal with CTG assessment and then overcome the limitations of the visual assessment of CTGs mentioned above, but clinical judgment remains highly dependent on CTG analysis [26]. Since all FHR processing and analysis in these systems is based on morphological features provided by FIGO guidelines, they lack the integration of nonlinear indices that would allow them to be optimized.

The ability to predict preterm labor can improve the wellbeing of both fetus and mother. The successful prediction of preterm labor is an essential part of a decision support system for physicians to implement measures that adequately reduce related fetal morbidity and mortality (like the administration of corticosteroids to the mother in order to accelerate lung maturation and therefore decrease the risk of respiratory distress in the newborn).

The main objective of this work is to evaluate how useful nonlinear parameters, namely entropy and compression, can be as labor predictors by using antepartum FHR and UC traces one or two weeks before labor.

\section{Materials and Methods}

\subsection{Nonlinear Methods}

\subsubsection{Compression}

The Kolmogorov Complexity (KC) [27] is defined as the function mapping a string $x$ in an integer, bounded to a Turing Machine $\phi$. The KC reflects the increase in new patterns along a given sequence. 
In this case, the word complexity refers to the algorithmic complexity, defined according to information theory, as the length of the shortest program $\mathrm{p}$ able to print the string $x$.

$$
K C_{\phi}(x)=\left\{\begin{array}{c}
\min \{|p|: \phi(p)=x\}, \quad \text { if } \phi(p)=x \\
\infty \quad \text { if } p \text { does not exit }
\end{array}\right.
$$

For a random string, the output of the KC function will be the length of the original string, as any compression effort will end in information loss. On the other hand, the more reoccurring patterns, the less complex the string is.

Although this concept is objective, its applicability is limited by the fact that KC is not computable. Compressors are a close upper-bounded approximation of the $\mathrm{KC}$ function. For over 30 years, data compression software has been developed for data storage and transmission efficiency purposes. More recently, compression has been utilized in research fields like music, literature, internet traffic, and health [28-30].

In this work, we will assess the algorithmic complexity of FHR and UC signals by applying the Gzip compressor. Gzip [31] combines two classical algorithms-Lempel-Ziv (LZ77) [32], a dictionary based algorithm, and Huffman scheme [33] - by encoding sequences of high probability using shorter bits in comparison with lower probability strings, where longer bits are used. The amount of compression obtained depends on the input file size and the distribution of common substrings.

The idea is that for a given time series, the compression ratio (CR), i.e., the compressed size of the file divided by its original size, can be used to assess the complexity. A random series will have CR close to 1 , whereas a series full of patterns will be highly compressible and, therefore, the $C R$ will be close to 0 . The Gzip with maximum compression levels and values presented represents the percentage of CR.

\subsubsection{Entropy}

In 1991, Pincus developed the Approximate Entropy (ApEn), a regularity statistic tool used to quantify a system's complexity based on the notion of entropy [34]. The ApEn measures the irregularity of time series and is defined as the logarithmic likelihood that the patterns of a time series that are close to each other will remain close when longer patterns are compared.

Later, in 2000, Richman and Moorman [35] proposed Sample Entropy (SampEn). Similar to ApEn, the SampEn measures time series irregularity. However, it does so with some major advantages: (1) self-matches are not counted, reducing bias; (2) it agrees much better than ApEn statistics with the theory for random numbers with known probabilistic character over a broad range of operating conditions; (3) the conditional probabilities are not estimated in a template manner. Instead, they are computed directly as the logarithm of conditional probability rather than from the ratio of the logarithmic sums, showing relative consistency in cases where ApEn does not [36].

To use either ApEn or SampEn, decisions on two different parameters, $m$, and $r$, have to be made. The $m$ parameter is the embedding dimension, i.e., the length of sequences to be compared, while the tolerance parameter $r$ works as a similarity threshold. Two patterns are considered similar if the difference between any pair of corresponding measurements is less than or equal to $r$. Values of 0.1 , 0.15 , or 0.2 standard deviations (SD) are usually used for parameter $r$, while $m$ is mostly considered as 2 [37]. In this work, tolerance of $0.1 \mathrm{SD}$ and an embedding dimension of 2 were used.

\subsection{Data}

The FHR data used for this study were from a retrospective cross-sectional study [38]. Each FHR trace corresponds to distinct fetuses from a singleton pregnancy. The selected traces were acquired between July 2005 and November 2010 during hospitalization in a tertiary care university hospital. All traces were acquired at least $48 \mathrm{~h}$ before delivery to guarantee they included no labor time. 
Furthermore, the traces included were at least 20 min long, during which the signal quality was over $80 \%$, and the signal loss was less than $33 \%$.

The cardiotocographic signals were acquired using an external ultrasound sensor applied to the maternal abdomen. The ultrasound signal is filtered, envelope rectified and digitized at a sampling rate of $800 \mathrm{~Hz}$ with a 12-bit precision [39]. Then, an autocorrelation function is used to calculate the heart period and the similarity between pulses of two consecutive heartbeats, as described in [40]. Via the digital outputs of the fetal monitors, resulting traces were analyzed using the Omniview SisPorto ${ }^{\circledR} 3.7$ system [23] at a sampling rate of $4 \mathrm{~Hz}$ (Figure 1).

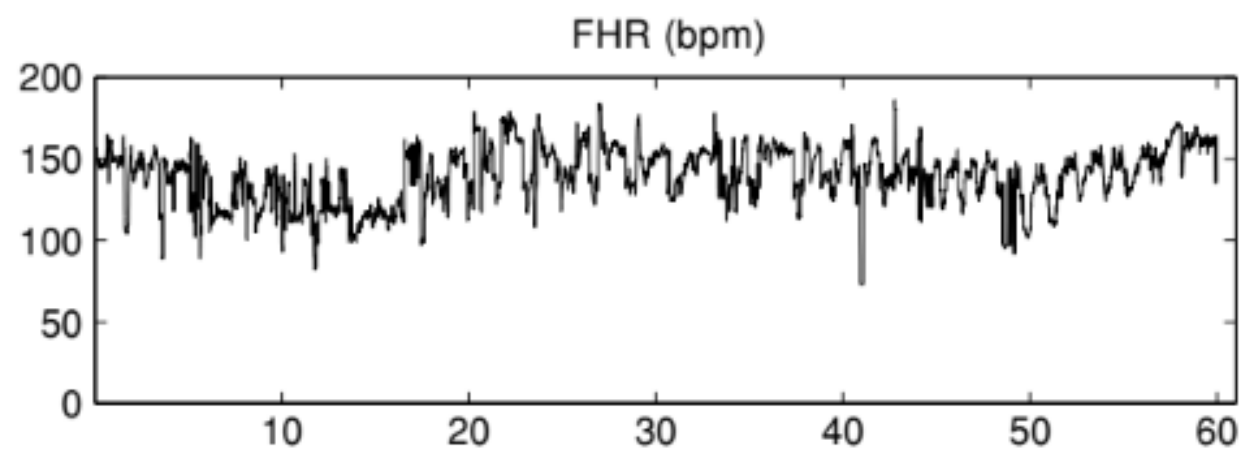

Figure 1. Example of a fetal heart rate (FHR) time series.

SisPorto features used in this paper are summarily described in Table 1. Note that the SisPorto system does not perform any average or reduction in FHR/UC signals.

Table 1. Description of SisPorto features [22,24].

\begin{tabular}{|c|c|}
\hline SisPorto Variable & Description \\
\hline Basal line FHR & $\begin{array}{l}\text { mean level of the most horizontal and less oscillatory FHR segments, in the absence of fetal } \\
\text { movements and uterine contraction (UC), associated with periods of fetal rest, estimated } \\
\text { via a complex algorithm }\end{array}$ \\
\hline baseline & approximation of basal FHR to long-term FHR fluctuations using running averaging \\
\hline $\begin{array}{l}\text { number of accelerations } \\
\text { (nAccel) }\end{array}$ & $\begin{array}{l}\text { number of increases in FHR over the baseline lasting } 15-120 \mathrm{~s} \text { and reaching a peak of at } \\
\text { least } 15 \mathrm{bpm} \text { in } 60 \mathrm{~min}\end{array}$ \\
\hline $\begin{array}{l}\text { number of contractions } \\
\text { (nContr) }\end{array}$ & $\begin{array}{l}\text { number of periods in } 60 \mathrm{~min} \text {, lasting a maximum of } 254 \mathrm{~s} \text {, where an upward slope } \\
\text { exceeding } 17 \mathrm{~s} \text { was detected reaching a peak lasting more than } 90 \mathrm{~s} \text {, followed by a } \\
\text { downward slope exceeding } 17 \mathrm{~s}\end{array}$ \\
\hline $\begin{array}{c}\text { number of mild } \\
\text { decelerations (mDec) }\end{array}$ & $\begin{array}{l}\text { number of decreases in FHR under the baseline lasting 15-120 s, with a minimum } \\
\text { amplitude of } 15 \mathrm{bpm} \text { in } 60 \mathrm{~min}\end{array}$ \\
\hline $\begin{array}{l}\text { number of intermediate } \\
\text { decelerations (iDec) }\end{array}$ & $\begin{array}{l}\text { number of decreases in FHR under the baseline lasting } 120-300 \mathrm{~s} \text {, with a minimum } \\
\text { amplitude of } 15 \mathrm{bpm} \text { in } 60 \mathrm{~min}\end{array}$ \\
\hline $\begin{array}{l}\text { number of prolonged } \\
\text { decelerations (pDec) }\end{array}$ & number of decelerations lasting more than $300 \mathrm{~s}$ in $60 \mathrm{~min}$ \\
\hline $\begin{array}{l}\text { average short-term } \\
\text { variability (avSTV) }\end{array}$ & $\begin{array}{l}\text { mean difference between adjacent FHR signals at } 4 \mathrm{~Hz} \text { on the fetal monitor, after removal } \\
\text { of adjacent signals that differ }>15 \mathrm{bpm}\end{array}$ \\
\hline $\begin{array}{l}\text { abnormal short-term } \\
\text { variability (abSTV) }\end{array}$ & percentage of subsequent FHR signals differing $<1 \mathrm{bpm}$ \\
\hline $\begin{array}{l}\text { average long-term } \\
\text { variability (avLTV) }\end{array}$ & $\begin{array}{l}\text { mean difference between max and min FHR in a } 1 \text { min sliding window, in segments free of } \\
\text { accelerations or deceleration }\end{array}$ \\
\hline $\begin{array}{l}\text { abnormal long-term } \\
\text { variability (abLTV) }\end{array}$ & $\begin{array}{l}\text { percentage of FHR signals with a difference between minimum } \\
\text { and maximum values in a surrounding } 1 \text { min window }<5 \mathrm{bpm}\end{array}$ \\
\hline
\end{tabular}

The 1072 traces selected ranged from 30 to 35 gestational weeks. Two groups were defined: Group A-fetuses whose traces date was less than two weeks before labor, and Group B-fetuses whose traces date was at least two weeks before labor. Physiological fetal and maternal features, such as maternal 
age (mAge) and baby gender, as well as some tracing characteristics such as trace duration and signal quality, were compared in both groups. Linear indices for uterine contraction analysis comprised of mean_UC (median of UC mean from 10min nonoverlapping blocks), sd_UC (median of UC standard deviation from 10min nonoverlapping blocks) and cv_UC (coefficient of variability of UC).

Two complexity measures, Gzip and SampEn, were considered in this work. Because the value of these measures depends on the trace size, each tracing was split into non-overlapping blocks of $10 \mathrm{~min}$. Both Gzip and SampEn were computed for each block. Then, the median value of CR and SampEn for each fetus was used. Both complexity measures were calculated for FHR (Gzip_FHR and SampEn_FHR) and UC signals (Gzip_UC and SampEn_UC).

\subsection{Statistical Analysis}

Normality for continuous variables was evaluated by visual inspection of the frequency distribution (histogram). For normally distributed variables, the values for each group are presented as mean $\pm S D$, and an independent samples t-test was performed. On the other hand, for skewed continuous variables, the values are presented as median (minimum-maximum), and the Mann-Whitney test was used to compare the two groups. The categorical variables were compared in the two groups applying the Chi-Square test or Fisher's exact test as applicable.

Logistic regression, using Hosmer-Lemeshow to test the goodness of fit, was used to predict which fetuses will be born preterm in the next two weeks. Variables were selected using Wald's backwards method. The concordance statistic (C-statistic), measured by the area under the receiver operating characteristic curve, was computed to assess the model's discrimination.

Akaike Information Criterion (AIC), AIC $=2 k-2 \log (L)$, where $k$ is the number of parameters and $L$ the maximum value of the likelihood function, was used for model comparison, where a lower result suggests a better model.

Statistical analysis was performed with IBM SPSS Statistics for Windows, version 24 (IBM, Armonk, NY, USA).

\section{Results}

A total of 1072 antepartum tracings were used, 96 of which were born in the following two weeks (Group A). The main clinical characteristics of the group in which fetuses were born in the next two weeks (Group A) and the group in which they were not (Group B) are presented and compared in Table 2. Note that no differences were found between the groups for these variables.

Table 2. Fetal and maternal features from Group A-fetuses whose traces date was less than two weeks before labor, and Group B-fetuses whose traces date was at least two weeks before labor.

\begin{tabular}{cccc}
\hline & $\begin{array}{c}\text { Group A (n= 96) } \\
\text { Median (min-max), } \\
\text { Mean } \pm \text { SD or N (\%) }\end{array}$ & $\begin{array}{c}\text { Group B (n= 976) } \\
\text { Median (min-max), } \\
\text { Mean } \pm \text { SD or N (\%) }\end{array}$ & $p$-Value \\
\hline Trace duration (min) & $25.56(14.82-67.07)$ & $25.18(11.28-96.31)$ & 0.905 \\
\hline Gestational age at delivery (weeks) & $36.58 \pm 1.12$ & $38.92 \pm 1.20$ & \\
\hline Maternal age (years) & $31(16-43)$ & $31(15-52)$ & 0.291 \\
\hline Cesarean section & $31(32.3)$ & $321(32.9)$ & 0.067 \\
\hline Baby presentation (cephalic) & $90(93.8)$ & $918(94.1)$ & 0.524 \\
\hline Gender (male) & $49(51)$ & $506(51.8)$ & 0.881 \\
\hline Signal quality (\%) & $97(80-100)$ & $96(80-100)$ & 0.105 \\
\hline Signal loss (\%) & $3(0-20)$ & $4(0-21)$ & 0.106 \\
\hline
\end{tabular}


SisPorto features were also compared between the two groups (Table 3). Statistical significance was found with variables iDec $(p<0.001)$, which was lower in fetuses who would be born in the next two weeks, and average long-term variability (abLTV), which was higher in fetuses who would be born in the next two weeks $(p=0.038)$.

Furthermore, while SampEn was not able to find differences between the traces from babies in the two groups with FHR and UC signals, Gzip was ( $p=0.024$ for FHR, $p=0.013$ for UC), being lower in fetuses who would be born in the next two weeks (Group A) for FHR signals, while the opposite happened for UC signals. The standard deviation of UC was also significantly higher for Group A $(p=0.020)$.

Table 3. SisPorto and nonlinear features from Group A-fetuses whose traces date were less than two weeks before labor, and Group B-fetuses whose traces date were at least two weeks before labor.

\begin{tabular}{|c|c|c|c|}
\hline & $\begin{array}{c}\text { Group A }(\mathrm{n}=96) \\
\text { Median (min-max), } \\
\text { Mean } \pm \text { SD or N (\%) }\end{array}$ & $\begin{array}{c}\text { Group B }(n=976) \\
\text { Median (min-max), } \\
\text { Mean } \pm \text { SD or N }(\%)\end{array}$ & $p$-Value \\
\hline Basal line & $133(108-154)$ & $134(105-168)$ & 0.137 \\
\hline Baseline & $135.5(114-160)$ & 137 (105-169) & 0.237 \\
\hline nAccel & $5(0-13)$ & $5(0-31)$ & 0.188 \\
\hline nContr & $1(0-15)$ & $1(0-15)$ & 0.200 \\
\hline $\mathrm{mDec}$ & $0(0-5)$ & $0(0-13)$ & 0.787 \\
\hline iDec (\% of no iDec) & $89(92.71)$ & $962(98.57)$ & $<0.001$ \\
\hline $\mathrm{pDec}(\%$ of no $\mathrm{pDec})$ & $96(100)$ & $973(99.69)$ & 1.000 \\
\hline abSTV & $50.49 \pm 8.83$ & $50.27 \pm 8.42$ & 0.805 \\
\hline avSTV & $14.48 \pm 3.48$ & $14.55 \pm 3.45$ & 0.839 \\
\hline abLTV & $1(0-35)$ & $0(0-38)$ & 0.038 \\
\hline avLTV & $15.85(8-33)$ & $16.8(0-40)$ & 0.229 \\
\hline mean_UC & $172.504 \pm 103.426$ & $166.663 \pm 101.650$ & 0.592 \\
\hline sd_UC & $56.350 \pm 42.403$ & $45.768 \pm 35.096$ & 0.020 \\
\hline cv_UC & $0.424 \pm 0.347$ & $0.369 \pm 0.328$ & 0.121 \\
\hline Gzip_UC & $6.089 \pm 1.769$ & $5.664 \pm 1.568$ & 0.013 \\
\hline SampEn_UC & $0.547 \pm 0.306$ & $0.595 \pm 0.287$ & 0.117 \\
\hline Gzip_FHR & $11.559 \pm 0.995$ & $11.758 \pm 0.878$ & 0.024 \\
\hline SampEn_FHR & $0.670 \pm 0.159$ & $0.693 \pm 0.195$ & 0.265 \\
\hline
\end{tabular}

Logistic regression, including all relevant variables $(p<0.05)$-Gzip_FHR, Gzip_UC, sd_UC, iDec, a week of CTG (wCTG), and abLTV—was then performed using a backward selection model. The model obtained included the variables Gzip, iDec and a week of CTG (wCTG). Also, interactions between Gzip and wCTG were considered but found to be non-significant. Results from the logistic regression can be found in Table 4. 
Table 4. Logistic regression for labor prediction in two weeks or less.

\begin{tabular}{ccccc}
\hline & B & $p$-Value & Exp(B) & 95\% CI \\
\hline Constant & -20.639 & $<0.001$ & & \\
\hline wCTG & 0.674 & $<0.001$ & 1.962 & $1.489-2.584$ \\
\hline Gzip_FHR & -0.341 & 0.005 & 0.711 & $0.560-0.902$ \\
\hline iDec $^{\text {a }}$ & 1.782 & $<0.001$ & 5.950 & $2.217-15.918$ \\
\hline \multicolumn{5}{c}{${ }^{\text {a }}$ No iDec was set as reference instance. }
\end{tabular}

From this logistic regression model, abLTV and UC variables were removed from the initial set of predictors made by the model, and a C-statistic of 0.704 was obtained, with a $95 \%$ confidence interval range of $0.651-0.758$. Also, the AIC obtained for this model was 603.763. The process was repeated considering all relevant physiological and linear features but without Gzip. This model, now without Gzip but with abLTV, achieved an AIC of 605.5 and a C-statistic of 0.691 (0.639-0.742).

The groups were also redefined and tested again. The same analysis as before was performed, except Group A consisted of fetuses who were born less than one week (instead of two weeks) from trace acquisition ( $n=27$, all preterm) and Group B consisted of all other fetuses ( $n=1045$, term and preterm babies), which were born as term and preterm babies. SisPorto and nonlinear features were compared between the groups, as carried out in our previous analysis (results in Appendix A).

The logistic regression results are shown in Table 5. Note that the same variables were included in the logistic regression.

Table 5. Logistic regression for labor prediction in one week or less.

\begin{tabular}{ccccc}
\hline & B & $p$-Value & $\operatorname{Exp(B)}$ & $\mathbf{9 5 \%}$ CI \\
\hline Constant & -6.679 & 0.330 & & \\
\hline wCTG & 0.317 & 0.097 & 1.373 & $0.944-1.997$ \\
\hline Gzip_FHR & -0.573 & 0.010 & 0.564 & $0.364-0.873$ \\
\hline iDec & 2.780 & $<0.001$ & 16.112 & $5.205-49.874$ \\
\hline
\end{tabular}

This model achieved an AIC of 235.3 and a C-statistic of 0.728 (0.619-0.836), which is a small improvement compared with the first one described in this paper.

In Table 6, Spearman's correlation coefficient between Gzip and different physiological measures of variability was calculated. Moreover, the same coefficient was calculated for each group. Statistically significant results were found for abLTV and avLTV for two weeks labor prediction.

Table 6. Spearman's correlation coefficient and respective $95 \%$ confidence interval (CI) between Gzip_FHR and short- and long-term variabilities given by SisPorto. Confidence intervals were calculated using bootstrapping. Bold means significant differences between groups.

\begin{tabular}{cccccc}
\hline & & \multicolumn{2}{c}{ Two Weeks Prediction } & \multicolumn{2}{c}{ One Week Prediction } \\
\hline \multirow{2}{*}{ Total } & Group A & Group B & Group A & Group B \\
\hline \multirow{2}{*}{ abSTV } & $-0.524(-0.564 ;$ & $-0.636(-0.733 ;$ & $-0.512(-0.565 ;$ & $-0.694(-0.867 ;$ & $-0.515(-0.560 ;$ \\
& $-0.481)$ & $-0.501)$ & $-0.463)$ & $-0.370)$ & $-0.468)$ \\
\hline \multirow{2}{*}{ avSTV } & $0.500(0.452 ;$ & $0.596(0.442 ;$ & $0.489(0.437 ;$ & $0.698(0.410 ;$ & $0.492(0.444 ;$ \\
& $0.541)$ & $0.720)$ & $0.539)$ & $0.864)$ & $0.539)$ \\
\hline \multirow{2}{*}{ abLTV } & $-0.562(-0.602 ;$ & $-\mathbf{0 . 7 2 2 ( - 0 . 8 0 7 ;}$ & $-\mathbf{0 . 5 4 1 ( - 0 . 5 8 9 ;}$ & $-0.760(-0.893 ;$ & $-0.551(-0.596 ;$ \\
& $-0.520)$ & $-\mathbf{0 . 6 0 1 )}$ & $-\mathbf{0 . 4 9 5 )}$ & $-0.489)$ & $-0.509)$ \\
\hline \multirow{2}{*}{ avLTV } & $0.765(0.737 ;$ & $\mathbf{0 . 8 8 5 ( 0 . 8 1 8 ;}$ & $\mathbf{0 . 7 5 1 ( 0 . 7 1 8 ;}$ & $0.874(0.663 ;$ & $0.760(0.730 ;$ \\
& $0.792)$ & $\mathbf{0 . 9 2 4 )}$ & $\mathbf{0 . 7 8 0 )}$ & $0.970)$ & $0.789)$ \\
\hline
\end{tabular}




\section{Discussion}

This study enhances the importance of the inclusion of nonlinear indices in clinical practice. In particular, the results suggest that the Gzip compression ratio, a measure of the time series complexity, may improve the predictability of labor onset when applied to FHR and UC signals.

The main objective of this work was to predict labor within two weeks. Both groups included preterm and term babies. In Group A, 46 of 90 were term babies, born between 36 and 37 weeks of gestational age; while in Group B, 44 of 976 fetuses were preterm. No statistical significance was found between term and preterm cases in Group A or Group B.

The information captured by compression relates to the information comprised of other physiological features, such as short and long term variabilities [41]. In our study, Gzip_FHR has a Spearman's correlation coefficient of -0.524 and 0.5 with abSTV and avSTV's variabilities, respectively. These results contrast with a previous study [41] where correlation values were much higher in absolute value ( -0.851 and 0.774$)$. Some different characteristics of the datasets used in each study can explain these differences. On the one hand, the dataset of our study was acquired in an antepartum setting, while the data from the previous study were recorded during the intrapartum. In line with this, the difference observed in the two studies suggests that compression looks at physiological regulatory mechanisms that differ between both settings. On the other hand, another possible explanation is the different sampling rates used in the two studies $(4 \mathrm{~Hz}$ here, versus $2 \mathrm{~Hz}$ in the other study). This may indicate that some information is lost when using $2 \mathrm{~Hz}$. This inkling is supported by the results of Gonçalves et al. [42], who found nonlinear differences between both sampling rates. However, the study of Gonçalves et al. [42] is an intrapartum study, and the tolerance parameter for entropy was computed using an automatic threshold proposed by $\mathrm{Lu}$ [43]. A multiscale analysis of scale two would be affected by the latter hypothesis (as it mimics a $2 \mathrm{~Hz}$ sampling rate), but in our study, no difference was found. Govindan et al. [44] suggested a different approach, modifying the definition of sample entropy using a time delay. Future studies should compare several methods to study the oversampling question.

When factoring by group, we found significant differences in correlations between Gzip and abLTV and avLTV (Table 6). Different studies [45-48] found HRV changes, such as variability increase and pattern formation throughout fetal maturation, captured by nonlinear indices. Here, different patterns arise in the two groups presented, meaning that compression attains different information from HRV when compared with usual metrics. However, no statistical significance was found in one-week labor prediction analysis. We believe this might be due to low statistical power, as the number of individuals in Group A was 27, making confidence intervals too wide.

Some papers $[49,50]$ indicate different gender development throughout gestation and suggest taking this into account in model creation. Though it was taken into consideration, no significant results were found.

The mean compression ratio (instead of median) of the tracings' block was also considered, and the results obtained were similar. These results suggest robustness of compression regarding skewness and outliers, as well as low intra-tracing variability. Furthermore, multiscale analysis [51] was also performed both for SampEn and Gzip up to five scales, since we were using intervals of $10 \mathrm{~min}(\sim 1440$ data points), but no improvement was found.

Two different definitions for the groups were tested. The same analysis as before was performed, considering Group A as babies who were born preterm less than two weeks, and then less than one week, from trace acquisition $(n=27)$. As shown in Tables 4 and 5 , the logistic regression included the same variables. A small improvement was verified when considering one week, compared with two weeks, from labor. These results reinforce the stability of compression when predicting labor time.

Nonlinear FHR features recognition is a problem in the clinical community because clinicians do not always know how to interpret it. Although entropy has been associated with the activity of central nervous system regulation [52,53], there are still no direct associations between compression and the fetus' physiology. Compression looks for patterns in the series, and a healthy fetus is linked 
with a high compression ratio (a more chaotic signal leads to fewer patterns that are able to be compressed). In contrast, an unhealthy fetus, under the response of its regulatory system, creates a heart rate signal with more patterns, leading to a lower compression ratio. There is evidence that sympatho-vagal activity, and probably also central nervous system activity, are associated with the onset and progression of labor, namely via sympathetic activation and vagal inhibition mechanisms [16]. A continuous decrease in the sympathetic stress response during the last weeks before labor was also reported [54], contrary to a stable baseline sympathetic level. Being able to find links between these events and nonlinear indices is key for medical acceptance of these tools in daily practice. Therefore, it is imperative that a more thorough analysis of the FHR changes captured by compression is carried out in particular.

These results are relevant since an early prediction of labor as a decision support system for physicians can improve both fetus and mother assessment and care. In particular, being capable of predicting preterm labor is of extreme importance, as major risks to fetus and mother are associated with it.

This work has some limitations. The number of preterm cases is small, considering the week of the CTG variable is included. Because of this, only fetuses between weeks 30 and 35 of gestational age were selected, limiting the interpretability of the results. Although all the cases were hospitalized, no knowledge of the hospitalization cause is known.

Future studies should validate these models in larger datasets and, if possible, test them in different settings, such as during hospitalization and regular appointments.

\section{Conclusions}

Prediction of labor is of extreme importance since physicians will be able to take preventive measures to ensure that both baby and mother will be as prepared as possible. In this work, it was shown that nonlinear measures, compression in particular, can improve labor prediction.

Author Contributions: J.M.-S., T.H., and C.C.-S. substantial contribution to conception and design; T.H., C.C.-S., J.B., I.N., and C.A.-C. revise critically for important intellectual content; J.M.-S. and T.H. wrote the paper. All authors have read and agreed to the published version of the manuscript.

Funding: This work was supported by the project “Digi-NewB" funded from the European Union's Horizon 2020 research and innovation programme under grant agreement No 689260.

Acknowledgments: J. Santos acknowledges the support of the doctorate scholarship from the Clinical Research and Health Services Program, funded by the European Social Fund under the Portuguese Norte 2020 research and innovation program (grant agreement $\mathrm{n}^{\circ}$ Norte-08-5369-FSE-000063). The authors also acknowledge the SisPorto project based at the department of Obstetrics and Gynecology of the School of Medicine, University of Porto.

Conflicts of Interest: João Bernardes currently receives royalties from the development of the commercially available SisPorto system for CTG monitoring.

\section{Appendix A}

Table A1. SisPorto and nonlinear features from Group A-fetuses whose traces date were less than one week before labor, and Group B-fetuses whose traces date were at least one week before labor.

\begin{tabular}{cccc}
\hline & $\begin{array}{c}\text { Group A (n=27) } \\
\text { Median (min-max), } \\
\text { Mean } \pm \text { SD or N (\%) }\end{array}$ & $\begin{array}{c}\text { Group B (n = 1045) } \\
\text { Median (min-max), } \\
\text { Mean } \pm \text { SD or N (\%) }\end{array}$ & $p$-Value \\
\hline Baseline & $134(123-160)$ & $137(105-169)$ & 0.507 \\
\hline Basal line & $130(122-146)$ & $134(105-168)$ & 0.234 \\
\hline nAccel & $5(0-11)$ & $5(0-31)$ & 0.714 \\
\hline nContr & $1(0-11)$ & $1(0-15)$ & 0.246 \\
\hline mDec & $0(0-2)$ & $0(0-13)$ & 0.175 \\
\hline iDec $(\%$ of no iDec) & $22(81.48)$ & $1029(98.47)$ & $<\mathbf{0 . 0 0 1}$ \\
\hline
\end{tabular}


Table A1. Cont.

\begin{tabular}{cccc}
\hline pDec $(\%$ of no pDec $)$ & $27(100)$ & $1042(99.71)$ & 1.000 \\
\hline abSTV & $52.89 \pm 8.95$ & $50.22 \pm 8.44$ & 0.105 \\
\hline avSTV & $13.78 \pm 3.65$ & $14.57 \pm 3.44$ & 0.240 \\
\hline abLTV & $3(0-31)$ & $0(0-38)$ & $\mathbf{0 . 0 1 2}$ \\
\hline avLTV & $14.7(8-33)$ & $16.8(0-40)$ & 0.126 \\
\hline mean_UC & $161.167 \pm 138.37$ & $167.342 \pm 100.739$ & 0.756 \\
\hline sd_UC & $55.844 \pm 44.593$ & $46.480 \pm 35.659$ & 0.181 \\
\hline cv_UC & $0.463 \pm 0.329$ & $0.372 \pm 0.329$ & 0.155 \\
\hline Gzip_UC & $6.132 \pm 1.981$ & $5.691 \pm 1.579$ & 0.261 \\
\hline SampEn_UC & $0.537 \pm 0.269$ & $0.592 \pm 0.290$ & 0.325 \\
\hline Gzip_FHR & $11.356 \pm 1.089$ & $11.750 \pm 0.883$ & $\mathbf{0 . 0 2 3}$ \\
\hline SampEn_FHR & $0.655 \pm 0.149$ & $0.692 \pm 0.193$ & 0.320 \\
\hline
\end{tabular}

\section{References}

1. Lawn, J.E.; Blencowe, H.; Oza, S.; You, D.; Lee, A.C.; Waiswa, P.; Lalli, M.; Bhutta, P.Z.; Barros, A.J.; Christian, P. Every newborn: Progress, priorities, and potential beyond survival. Lancet 2014, 384, 189-205. [CrossRef]

2. Liu, L.; Oza, S.; Hogan, D.; Perin, J.; Rudan, P.; Lawn, P.J.E.L.; Cousens, P.S.; Mathers, C.; Robert, P. Global, regional, and national causes of child mortality in 2000-13, with projections to inform post-2015 priorities: An updated systematic analysis. Lancet 2015, 385, 430-440. [CrossRef]

3. Blencowe, H.; Cousens, S.; Chou, D.; Oestergaard, M.; Say, L.; Moller, A.-N.; Kinney, M.; Lawn, J. Born too soon: The global epidemiology of 15 million preterm births. Reprod. Health 2013, 10, S2. [CrossRef] [PubMed]

4. Lawn, J.E.; Gravett, M.G.; Nunes, T.M.; Rubens, C.E.; Stanton, C. Global report on preterm birth and stillbirth (1 of 7): Definitions, description of the burden and opportunities to improve data. BMC Pregnancy Childbirth 2010, 10, S1. [CrossRef] [PubMed]

5. Mwaniki, M.K.; Atieno, M.; Lawn, J.E.; Newton, C.R.J.C. Long-term neurodevelopmental outcomes after intrauterine and neonatal insults: A systematic review. Lancet 2012, 379, 445-452. [CrossRef]

6. Ayres-De-Campos, D.; Bernardes, J.; Costa-Pereira, A.; Pereira-Leite, L. Inconsistencies in classification by experts of cardiotocograms and subsequent clinical decision. Br. J. Obstet. Gynaecol. 1999, 106, 1307-1310. [CrossRef] [PubMed]

7. Bernardes, J.; Ayres-de-Campos, D. The persistent challenge of foetal heart rate monitoring. Curr. Opin. Obstet. Gynecol. 2010, 22, 104-109. [CrossRef]

8. Spencer, J.A. Role of cardiotocography. Br. J. Hosp. Med. 1992, 48, 115-118.

9. Goncalves, H.; Pinto, P.; Ayres-de-Campos, D.; Bernardes, J. External uterine contractions signal analysis in relation to labor progression and dystocia. IFMBE Proc. 2014, 41, 555-558.

10. Goncalves, H.; Morais, M.; Pinto, P.; Ayres-de-Campos, D.; Bernardes, J. Linear and non-linear analysis of uterine contraction signals obtained with tocodynamometry in prediction of operative vaginal delivery. J. Perinat. Med. 2017, 45, 327-332. [CrossRef]

11. Bernardes, J.; Costa-Pereira, A.; Ayres-de-Campos, D.; van Geijn, H.P.; Pereira-Leite, L. Evaluation of interobserver agreement of cardiotocograms. Int. J. Gynecol. Obstet. 1997, 57, 33-37. [CrossRef]

12. Donker, D.K.; Vangeijn, H.P.; Hasman, A. Interobserver variation in the assessment of fetal heart-rate recordings. Eur. J. Obstet. Gynecol. Reprod. Biol. 1993, 52, 21-28. [CrossRef]

13. Schiermeier, S.; von Steinburg, S.P.; Thieme, A.; Reinhard, J.; Daumer, M.; Scholz, M.; Hatzmann, W.; Schneider, K. Sensitivity and specificity of intrapartum computerised FIGO criteria for cardiotocography and fetal scalp pH during labour: Multicentre, observational study. BJOG Int. J. Obstet. Gynaecol. 2008, 115, 1557-1563. [CrossRef] [PubMed]

14. Plsek, P.E.; Greenhalgh, T. Complexity science-The challenge of complexity in health care. Br. Med. J. 2001, 323, 625-628. [CrossRef] [PubMed]

15. Parer, J.T. Handbook of Fetal Heart Rate Monitoring; W.B. Saunders Company: Philadelphia, PA, USA, 1997. 
16. Reinl, E.L.; England, S.K. Fetal-to-maternal signaling to initiate parturition. J. Clin. Investig. 2015, 125, 2569-2571. [CrossRef]

17. Rotmensch, S.; Liberati, M.; Vishe, T.; Celentano, C.; Ben-Rafael, Z.; Bellati, U. The effect of betamethasone and dexamethasone on fetal heart rate patterns and biophysical activities-A prospective randomized trial. Acta Obstet. Gynecol. Scand. 1999, 78, 493-500. [CrossRef]

18. Signorini, M.G.; Fanelli, A.; Magenes, G. Monitoring fetal heart rate during pregnancy: Contributions from advanced signal processing and wearable technology. Comput. Math. Methods Med. 2014, 2014, 707581. [CrossRef]

19. Nunes, I.; Ayres-de-Campos, D.; Figueiredo, C.; Bernardes, J. An overview of central fetal monitoring systems in labour. J. Perinat. Med. 2013, 41, 93-99. [CrossRef]

20. Wilson, T.; Holt, T. Complexity science-Complexity and clinical care. Br. Med. J. 2001, 323, 685-688. [CrossRef]

21. Chudacek, V.; Jiri, S.; Huptych, M.; Georgoulas, G.; Janku, P.; Koucky, M.; Stylios, C.; Lhotska, L. Automatic Classification of Intrapartal Fetal Heart-Rate Recordings-Can It Compete with Experts? In Proceedings of theInternational Conference on Information Technology in Bio-and Medical Informatics; Springer: Berlin/Heidelberg, Germany, 2010; pp. 57-66.

22. Ayres-de Campos, D.; Berbardes, J.; Garrido, A.; Marques-de-sa, J.; Pereira-Leite, L. SisPorto 2.0: A program for automated analysis of cardiotocograms. J. Matern. Fetal Med. 2000, 9, 311-318.

23. Ayres-de-Campos, D.; Sousa, P.; Costa, A.; Bernardes, J. Omniview-SisPorto 3.5-A central fetal monitoring station with online alerts based on computerized cardiotocogram+ST event analysis. J. Perinat. Med. 2008, 36, 260-264. [CrossRef] [PubMed]

24. Ayres-de-Campos, D.; Rei, M.; Nunes, I.; Sousa, P.; Bernardes, J. SisPorto 4.0-computer analysis following the 2015 FIGO Guidelines for intrapartum fetal monitoring. J. Matern. Fetal Neonatal Med. 2017, 30, $62-67$. [CrossRef] [PubMed]

25. Guijarro-Berdinas, B.; Alonso-Betanzos, A.; Fontenla-Romero, O. Intelligent analysis and pattern recognition in cardiotocographic signals using a tightly coupled hybrid system. Artif. Intell. 2002, 136, 1-27. [CrossRef]

26. Nunes, I.; Ayres-de Campos, D.; Austin, U.; Pina, A.; Philip, B.; Antony, N.; Simon, C.; Paulo, S.; Cristina, C.-S.; Joao, B. Central fetal monitoring with and without computer analysis a randomized controlled trial. Obstet. Gynecol. 2017, 129, 83-90. [CrossRef]

27. Kolmogorov, A.N. Three approaches to the definition of the concept "quantity of information". Probl. Peredachi Inf. 1965, 1, 1-11.

28. Cilibrasi, R.; Vitanyi, P.; de Wolf, R. Algorithmic clustering of music based on string compression. Comput. Music J. 2004, 28, 49-67. [CrossRef]

29. Cilibrasi, R.; Vitanyi, P.M.B. Clustering by compression. IEEE Trans. Inf. Theory 2005, 51, $1523-1545$. [CrossRef]

30. Wehner, S. Analyzing worms and network traffic using compression. J. Comput. Secur. 2005, 15, 303-320. [CrossRef]

31. Deutsch, P. DEFLATE Compressed Data Format Specification Version 1.3. R.F.C. 1951. 1996. Available online: https://www.rfc-editor.org/info/rfc1951 (accessed on 16 January 2020). [CrossRef]

32. Ziv, J.; Lempel, A. Universal Algorithm for Sequential Data Compression. IEEE Trans. Inf. Theory 1977, 23, 337-343. [CrossRef]

33. Huffman, D.A. A method for the construction of minimum-redundancy codes. Proc. Inst. Radio Eng. 1952, 40,1098-1101. [CrossRef]

34. Pincus, S.M. Approximate entropy as a measure of system complexity. Proc. Natl. Acad. Sci. USA 1991, 88, 2297-2301. [CrossRef] [PubMed]

35. Richman, J.S.; Moorman, J.R. Physiological time-series analysis using approximate entropy and sample entropy. Am. J. Physiol. Heart Circ. Physiol. 2000, 278, H2039-H2049. [CrossRef] [PubMed]

36. Richman, J.; Moorman, R. Time series analysis using approximate entropy and sample entropy. Biophys. J. 2000, 78, 218A. [CrossRef]

37. Goncalves, H.; Rocha, A.P.; Ayres-de-Campos, D.; Bernardes, J. Frequency domain and entropy analysis of fetal heart rate: Appealing tools for fetal surveillance and pharmacodynamic assessment of drugs. Cardiovasc Hematol. Disord Drug Targets 2008, 8, 91-98. [CrossRef] 
38. Amorim-Costa, C.; de Campos, D.A.; Bernardes, J. Cardiotocographic parameters in small-for-gestational-age fetuses: How do they vary from normal at different gestational ages? A study of 11687 fetuses from 25 to 40 weeks of pregnancy. J. Obstet. Gynaecol. Res. 2017, 43, 476-485. [CrossRef]

39. Hewlett-Packard. Hewlett-Packard Series 50 Service Manual. M1351A and 1353A. 1993. Available online: http://www.frankshospitalworkshop.com/equipment/documents/ecg/service_manuals/Philips_ Series_50_-_Service_manual.pdf (accessed on 16 January 2020).

40. Goncalves, H.; Rocha, A.P.; Ayres-de Campos, D.; Bernardes, J. Internal versus external intrapartum foetal heart rate monitoring: The effect on linear and nonlinear parameters. Physiol. Meas. 2006, 27, 307-319. [CrossRef]

41. Monteiro-Santos, J.; Goncalves, H.; Bernardes, J.; Antunes, L.; Nozari, M.; Costa-Santos, C. Entropy and Compression Capture Different Complexity Features: The Case of Fetal Heart Rate. Entropy 2017, 19, 688. [CrossRef]

42. Goncalves, H.; Costa, A.; Ayres-de-Campos, D.; Costa-Santos, C.; Rocha, A.P.; Bernaedes, J. Comparison of real beat-to-beat signals with commercially available $4 \mathrm{~Hz}$ sampling on the evaluation of foetal heart rate variability. Med. Biol. Eng. Comput. 2013, 51, 665-676. [CrossRef]

43. Lu, S.; Chen, X.; Kanters, J.K.; Solomon, I.C.; Chon, K.H. Automatic selection of the threshold value $\mathrm{r}$ for approximate entropy. IEEE Trans. Biomed. Eng. 2008, 55, 1966-1972.

44. Govindan, R.B.; Wilson, J.D.; Eswaran, H.; Lowery, C.L.; Peribl, H. Revisiting sample entropy analysis. Phys. Stat. Mech. Appl. 2007, 376, 158-164. [CrossRef]

45. Marzbanrad, F.; Kimura, Y.; Endo, M.; Palaniswami, M.; Khandoker, A.H. Transfer entropy analysis of maternal and fetal heart rate coupling. Conf. Proc. IEEE Eng. Med. Biol. Soc. 2015, 2015, 7865-7868.

46. Moraes, E.R.; Murta, L.O.; Baffa, O.; Wakai, R.T.; Comani, S. Linear and nonlinear measures of fetal heart rate patterns evaluated on very short fetal magnetocardiograms. Physiol. Meas. 2012, 33, 1563-1583. [CrossRef]

47. Padhye, N.S.; Brazdeikis, A.; Verklan, M.T. Change in complexity of fetal heart rate variability. Conf. Proc. IEEE Eng. Med. Biol. Soc. 2006, 1, 1796-1798.

48. Van Leeuwen, P.; Cysarz, D.; Edelhauser, F.; Gronemeyer, D. Heart rate variability in the individual fetus. Auton Neurosci. 2013, 178, 24-28. [CrossRef]

49. Bernardes, J.; Goncalves, H.; Ayres-de-Campos, D.; Rocha, A.P. Sex differences in linear and complex fetal heart rate dynamics of normal and acidemic fetuses in the minutes preceding delivery. J. Perinat. Med. 2009, 37, 168-176. [CrossRef]

50. Kim, K.N.; Park, Y.S.; Hoh, J.K. Sex-related differences in the development of fetal heart rate dynamics. Early Hum. Dev. 2016, 93, 47-55. [CrossRef]

51. Ferrario, M.; Signorini, M.G.; Magenes, G. New indexes from the fetal heart rate analysis for the identification of severe intra uterine growth restricted fetuses. Conf. Proc. IEEE Eng. Med. Biol. Soc. 2006, 1, 1458-1461.

52. Chourasia, V.S.T.; Anil, K. Fetal heart rate variability analysis from phonocardiographic recordings. J. Mech. Med. Biol. 2011, 11, 1315-1331. [CrossRef]

53. Pincus, S.M.; Viscarello, R.R. Approximate entropy: A regularity measure for fetal heart rate analysis. Obstet. Gynecol. 1992, 79, 249-255.

54. Hellgren, C.; Akerud, H.; Jonsson, M.; Poromaa, I.S. Sympathetic reactivity in late pregnancy is related to labour onset in women. Stress Int. J. Biol. Stress 2011, 14, 627-633. [CrossRef]

(C) 2020 by the authors. Licensee MDPI, Basel, Switzerland. This article is an open access article distributed under the terms and conditions of the Creative Commons Attribution (CC BY) license (http://creativecommons.org/licenses/by/4.0/). 